\title{
Experimental Study of Latent Heat Thermal Energy Storage System for Medium Temperature Solar Applications
}

\author{
Ashish Kumar ${ }^{1}$, Pardeep Shahi ${ }^{1}$, Sandip K Saha ${ }^{2}$ \\ ${ }^{1}$ Department of Energy Science and Engineering, Indian Institute of Technology Bombay \\ Mumbai- 400076, India \\ ashish_kumar388@iitb.ac.in; pardeepshahi90@gmail.com \\ ${ }^{2}$ Department of Mechanical Engineering, Indian Institute of Technology Bombay \\ Mumbai- 400076, India \\ sandip.saha@iitb.ac.in
}

\begin{abstract}
An experimental study of multitube latent heat energy thermal storage system (LHTES) for medium temperature solar applications is presented in this paper. Charging and discharging of commercial grade PCM (A164), which is stored in annulus of the shell and tube type LHTES, is performed by flowing HTF (Hytherm 600) through seven inner tubes. Process of heat transfer between HTF and PCM is observed by obtaining temperature contours with the help of interpolation technique. The impact of parameters, such as HTF inlet temperature and mass flow rate of HTF on the thermal efficiency of LHTES is investigated during charging and discharging. Maximum efficiency of $41.3 \%$ is found at the highest HTF inlet temperature $\left(200{ }^{\circ} \mathrm{C}\right)$ considered in this study. The performance is found to increase with increasing mass flow rate and maximum efficiency of $33 \%$ is found at the mass flow rate of $0.1 \mathrm{~kg} / \mathrm{s}$.
\end{abstract}

Keywords: Latent heat, PCM, Charging, Discharging, Efficiency.

\section{Introduction}

In the last three decades, increasing energy demand, depletion of fossil fuel and increasing fuel cost are the matters of concern. Hence, researchers are investigating on the alternative source of energy, especially renewable energy like wind, solar, tide etc. Among the alternative sources of energy, solar energy is advantageous as the variation in source is less compared to other renewable energies, especially wind. However, the solar radiation is also irregular in nature and it fluctuates throughout the daytime. Thermal energy storage (TES) can be the solution of this problem and required energy can be provided during non-availability of solar radiation. Among different kinds of thermal storage, latent heat thermal energy storage (LHTES), which uses phase change material (PCM) to store or release energy, could be useful as PCM contains high energy storage density per unit volume and can store energy within a tiny temperature difference. Smaller volume for a given amount of energy is the key advantage of the latent heat energy storage system compared to the other conventional storage systems. It can store heat at constant or near constant temperature, which corresponds to the transformation temperature of phase change material (PCM). The PCM-based latent heat storage can well be utilized if it is operated in the phase change region from solid to liquid or vice versa, where change in temperature is small. Hence this technique is suitable for cyclic operation.

Design of the PCM container and the thermal and geometrical parameters of the container required for a given amount of PCM should take into the consideration. These factors have important role in influencing the parameters of heat transfer. PCM can be stored in long thin heat pipes [1], cylindrical shell and tube containers [2-4], rectangular containers [5-6] and spherical and cylindrical capsule [7-8]. Rectangular and cylindrical containers are the most commonly used container. Among them, shell and tube system is widely used. Trp et al. [9] studied the numerical model of transient phase change problem during charging and discharging period for a shell and tube type thermal energy storage system. The validation of their numerical model was performed with experimental results. Different parameters were studied for the analysis of total energy stored and released during charging and discharging period, such as the effect of HTF inlet velocity and HTF inlet temperature and influence of latent heat thermal storage unit tube length and outer tube radius. Adine et al. [10] numerically and experimentally investigated shell-and-tube type latent heat storage unit (LHSU) consisting of a shell in which two-phase change materials, P116 $\left(T_{m}=50^{\circ} \mathrm{C}\right)$ and $n$-octadecane $\left(T_{m}=27.7\right.$ ${ }^{\circ} \mathrm{C}$ ) were filled and forced flow HTF was flowing through the tube. In order to compare the thermal performances of the latent heat storage unit using two phase change materials (LHSU2) and a single PCM (LHSU1), a mathematical model based on the conservation energy equations was developed and validated with the experimental data. Different key 
parameters were used for the numerical analyses to compare the thermal performances of the latent heat storage units using two PCMs and a single PCM, during charging process (melting). The effects of HTF inlet temperature (ranges from 50 to $60{ }^{\circ} \mathrm{C}$ ), mass flow rate of the HTF and proportion mass of PCMs were studied. Oroa and Gila [11] experimentally evaluated the effect of different phase change materials used for the thermal energy storage system in solar cooling and refrigeration applications. Synthetic thermal oil was used as a heat transfer fluid (HTF) and has a working temperature range from 100 to $400{ }^{\circ} \mathrm{C}$. Two different PCMs $d$-mannitol $\left(T_{m}=167^{\circ} \mathrm{C}\right)$ and hydroquinone $\left(T_{m}=\right.$ $172.2^{\circ} \mathrm{C}$ ) were used. The effect of HTF mass flow rate and HTF inlet temperature were studied for charging and discharging time for both the PCMs.

From a detailed literature review, it is found that most of the experiments were performed on the low temperature $\left(<100^{\circ} \mathrm{C}\right)$ applications with paraffin and a limited experimental work is reported on latent heat based storage system for medium temperature solar applications between $150{ }^{\circ} \mathrm{C}$ to $200{ }^{\circ} \mathrm{C}$. Hence, the scope of the present work is to perform experiments to evaluate the thermal performance of latent heat storage system at $\sim 200{ }^{\circ} \mathrm{C}$. To investigate the effect of PCM on the heat transfer fluid (HTF) temperature, a cycle composed of charging and discharging period of $1800 \mathrm{~s} \mathrm{each}$ is considered. Experiments are performed for various operating parameters such as HTF inlet temperature and HTF flow rate.

\section{Experimental Setup}

Figure 1 shows the schematic diagram of experimental setup. The experimental setup has the following components, (i) thermal storage system, (ii) electric heaters (each $500 \mathrm{~W}$ ), (iii) canned motor pump, (iv) expansion tank, (v) cooler, (vi) storage tank with expander and nozzle, (vii) 3-way valve, (viii) control panel and (ix) pumps for cooling canned motor pump and filling the setup. Temperature and pressure drop are measured by K-type thermocouples (measuring temperature range $=0-480{ }^{\circ} \mathrm{C}$, accuracy $= \pm 0.7^{\circ} \mathrm{C}$ ) and Yokogawa make differential pressure transmitter (accuracy of $\pm 0.1 \%$ of total pressure), respectively. Schematic of the experimental setup is shown in figure 1 . The flow rate of HTF is measured by Coriolis mass flow meter (accuracy of $\pm 0.2 \%$ of mass flow rate). Measurements obtained at a time interval of $1 \mathrm{~s}$ from the experiments are recorded using National instrument (NI) cRIO 9066. Heat loss to the surrounding is measured by four T-type thermocouples (measuring temperature range $=-75-350{ }^{\circ} \mathrm{C}$, accuracy $= \pm 0.2^{\circ} \mathrm{C}$ ) mounted on the aluminium sheet wrapped on the $40 \mathrm{~mm}$ thick glass wool to insulate the thermal storage.

The test component in the experimental setup is a shell and tube heat exchanger based storage system, where PCM is at the shell side and HTF is passing through seven pipes. The experimental setup is made of SS316 to prevent corrosion. The thermal storage has an outer diameter of $100 \mathrm{~mm}$ and length $800 \mathrm{~mm}$. Each HTF pipe (material: SS316) has an internal diameter of $10.4 \mathrm{~mm}$, and outer diameter of $16 \mathrm{~mm}$. As the thermal conductivity $(0.116 \mathrm{~W} / \mathrm{m} . \mathrm{K})$ of HTF is low, six internal fins are used on the inner wall of the pipes. These fins are created by Electro Discharge Machining (EDM). The dimensions of each fin are 1 (thickness) $\times 2.5$ (height) $\times 800$ (length) $\mathrm{mm}$. An expander is used before the PCM storage system to distribute the HTF equally in 7 internal pipes. The expander has a conical shape with length of $200 \mathrm{~mm}$ and the smaller diameter is $33.4 \mathrm{~mm}$ and the larger diameter as $100 \mathrm{~mm}$. A nozzle of same shape and dimension is attached after the storage system to collect HTF. Thermophysical properties of PCM, HTF and SS316 is detailed in table 1. 


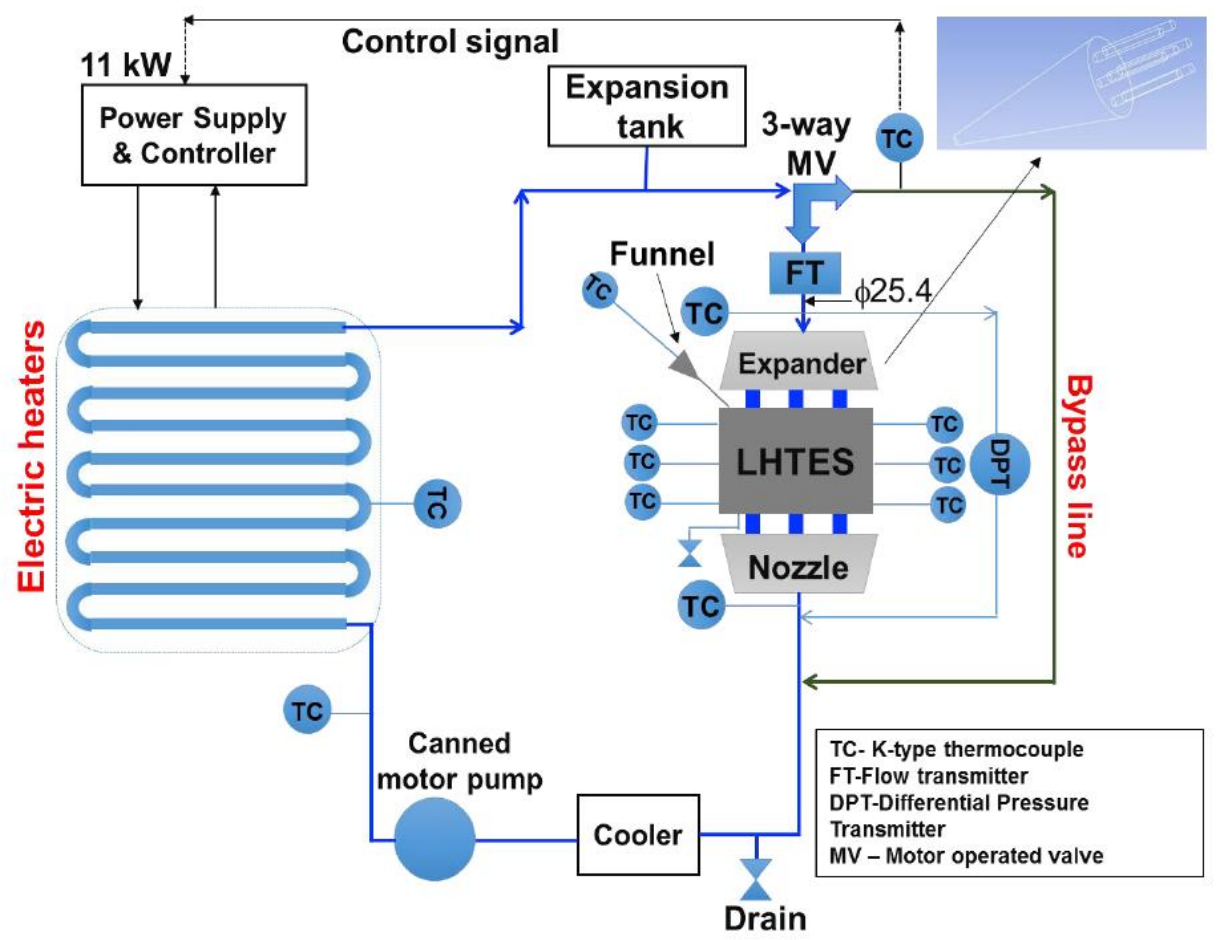

Fig. 1: Schematic of experimental setup.

Table 1: Thermophysical properties of PCM (A164), HTF (Hytherm) and Stainless steel [12].

\begin{tabular}{|c|c|c|c|}
\hline & PCM (A164) & HTF $($ Hytherm 600) & SS316 \\
\hline$c_{p}(\mathrm{~J} / \mathrm{kg} . \mathrm{K})$ & 2013 & 3097.4 & 502.48 \\
\hline$\rho\left(\mathrm{kg} / \mathrm{m}^{3}\right)$ & 1500 & 720.9 & 8030 \\
\hline$k(\mathrm{~W} / \mathrm{m} . \mathrm{K})$ & 0.425 & 0.116 & 16 \\
\hline$\mu(\mathrm{kg} / \mathrm{m} . \mathrm{s})$ & 0.0063 & 0.0195 & - \\
\hline$L(\mathrm{~J} / \mathrm{kg})$ & 249700 & - & - \\
\hline$\beta\left(\mathrm{K}^{-1}\right)$ & 0.00066 & - & - \\
\hline$T_{m}\left({ }^{\circ} \mathrm{C}\right)$ & 168.7 & - & \\
\hline
\end{tabular}

\section{Experimental Procedure}

One thermal cycle of experiments consists of starting mode, charging mode and discharging mode. The HTF is allowed to heat up to the desired temperature at which charging is required, along with this, PCM is allowed to heat slightly below the melting temperature $\left(\sim 162 \pm 2.5^{\circ} \mathrm{C}\right)$ using a tape heater attached on the outer surface of the storage system. Once the conditions are achieved, charging period begins and HTF is allowed to flow through the storage for $1800 \mathrm{~s}$ instead of bypass loop as shown in Figure 1. During discharging period of $1800 \mathrm{~s}$, the HTF is cooled to the desired temperature calculated from equation 1 by controlling cooler and heaters. Thermocouples measure temperatures at inlet and outlet of HTF and at different locations in PCM. Figure 2 shows the schematic of LHTES with location of thermocouples.

$$
T_{i n, d}=2 T_{m}-T_{i n, c}
$$

The efficiency of the LHTES is defined as,

$$
\eta=Q_{\text {out }, d} / Q_{\text {in }, c}
$$




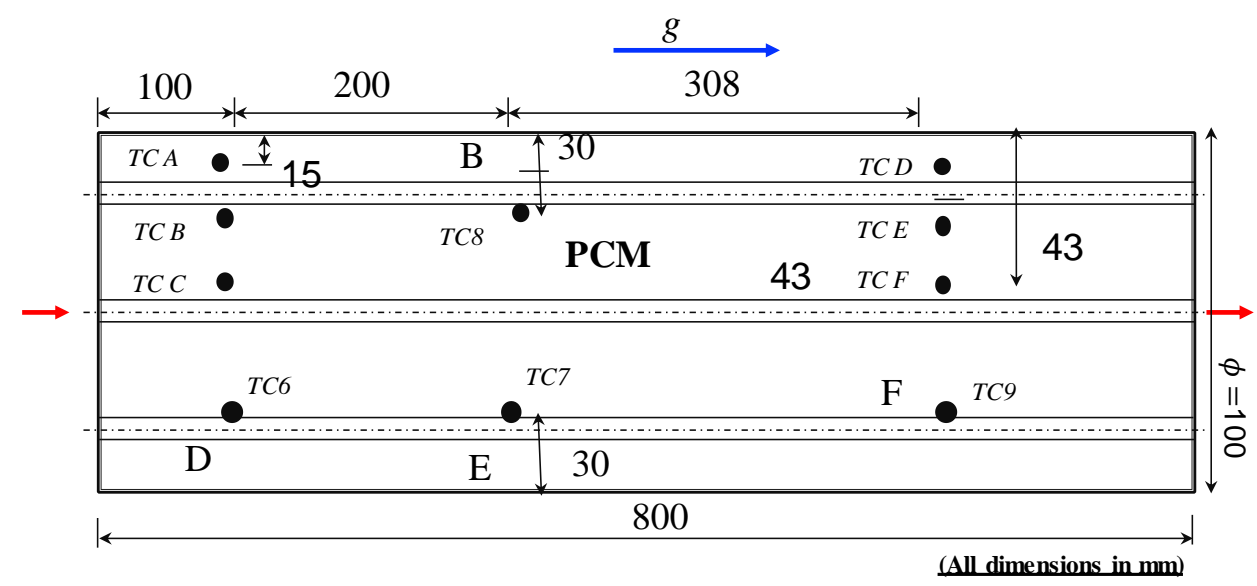

Fig. 2: Schematic of LHTES with thermocouple locations (all dimensions are in $\mathrm{mm}$ ).

\section{Repeatability of Experiment and Error Calculation}

Experiments on the lab-scale LHTES is repeated twice by maintaining the constant HTF inlet temperature of 200 ${ }^{\circ} \mathrm{C}$. The transient variation of HTF outlet temperature is monitored for $1800 \mathrm{~s}$ of charging, followed by the same period of discharging. The PCM is allowed to heat upto $162 \pm 2.5^{\circ} \mathrm{C}$ The flow rate is maintained at $0.85 \mathrm{~kg} / \mathrm{s}$. In discharging process, the inlet temperature of HTF is allowed to cool down upto $137.4{ }^{\circ} \mathrm{C}$ for next $1800 \mathrm{~s}$. Figure 3 shows the transient variation of HTF inlet and outlet temperatures for the charging and discharging processes. It can be observed that there is a slight variation in $T_{\text {in }}$ and $T_{\text {out }}$. The maximum difference in HTF inlet temperature between two experiments is 5.8 ${ }^{\circ} \mathrm{C}$. The outlet temperatures of HTF thus obtained during both the experiments are fairly following same trend with a maximum difference of $6.7^{\circ} \mathrm{C}$. At the start of charging process, the outlet temperature of HTF is $186{ }^{\circ} \mathrm{C}$ and then over time of $1800 \mathrm{~s}$ the HTF temperature increases. At the end of charging process, the HTF outlet temperature is found as 195.68 and $194.59^{\circ} \mathrm{C}$ for both the experiments. During discharging process, as the inlet temperature of HTF is reduced slowly from 200 to $137.4{ }^{\circ} \mathrm{C}$ over the time from 1800 to 3600 s. In discharging period, the PCM releases heat to the HTF, hence it is expected that the HTF outlet temperature should be more than the inlet temperature of HTF. However, this phenomenon is observed when the HTF inlet temperature reaches about $190{ }^{\circ} \mathrm{C}$ in $200 \mathrm{~s}$. This can be understood by the PCM temperature which is 194 and $190{ }^{\circ} \mathrm{C}$ at the two thermocouple locations (TC6 and TC9 as shown in figure 5) situated at the top and bottom of the tank. Hence it is said that the actual discharging process starts when the HTF temperature reaches below the average PCM temperature with is about $192{ }^{\circ} \mathrm{C}$ after the completion of charging process. The PCM temperature at two thermocouple locations for both the experiments are shown in figure 4 and 5. The PCM temperatures for both the experiments are observed to be almost same. The PCM temperature at TC6 location is high as compared to the location of TC9, due to positioning of two thermocouples. Thermocouple TC6 is located at the top of the tank, thus more heat transfer occurs at TC6 while TC 9 is the bottom of the multitube PCM tank. The maximum deviation in PCM temperature in different experiments at TC6 and TC9 is 6.4 and $3.7^{\circ} \mathrm{C}$, respectively, which is due to the difference in HTF inlet temperature in two experiments.

For the better understanding of repeatability error analysis is done to get the absolute error. Absolute Error is defined as:

$$
E_{a b s}=\left|T_{e x p}-T_{a v g}\right|
$$

where $T_{\text {exp }}$ is the temperature measured at a location during experiments at a time $t$ and $T_{\text {avg }}$ is the average temperature at same location after repetitive experiments. The absolute error in inlet and outlet temperatures of HTF is found to be 3.6 and $3.2^{\circ} \mathrm{C}$. 


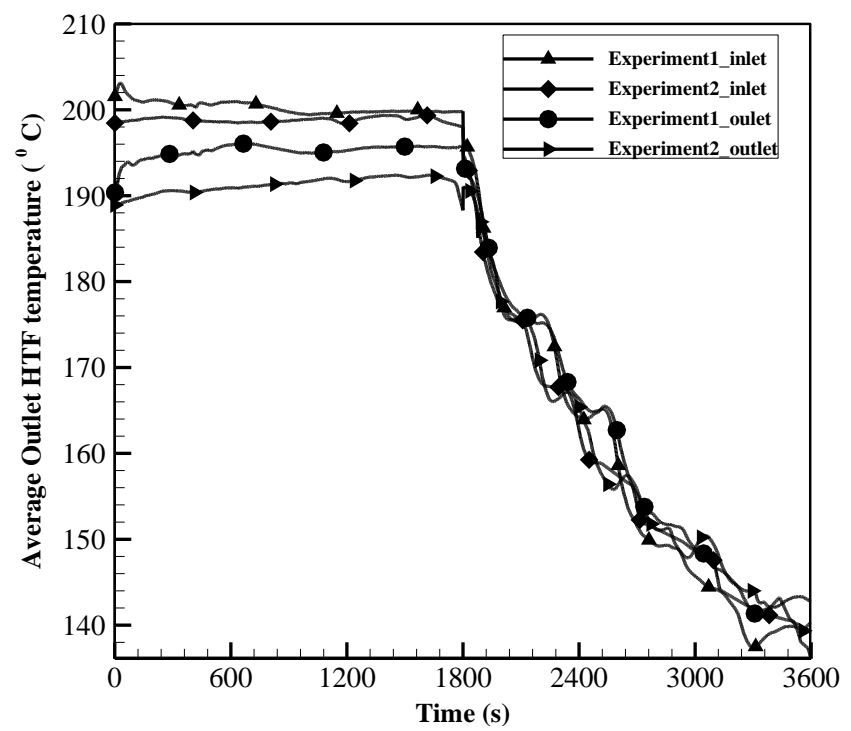

Fig. 3: Variation of HTF outlet temperature with time for two experiments.

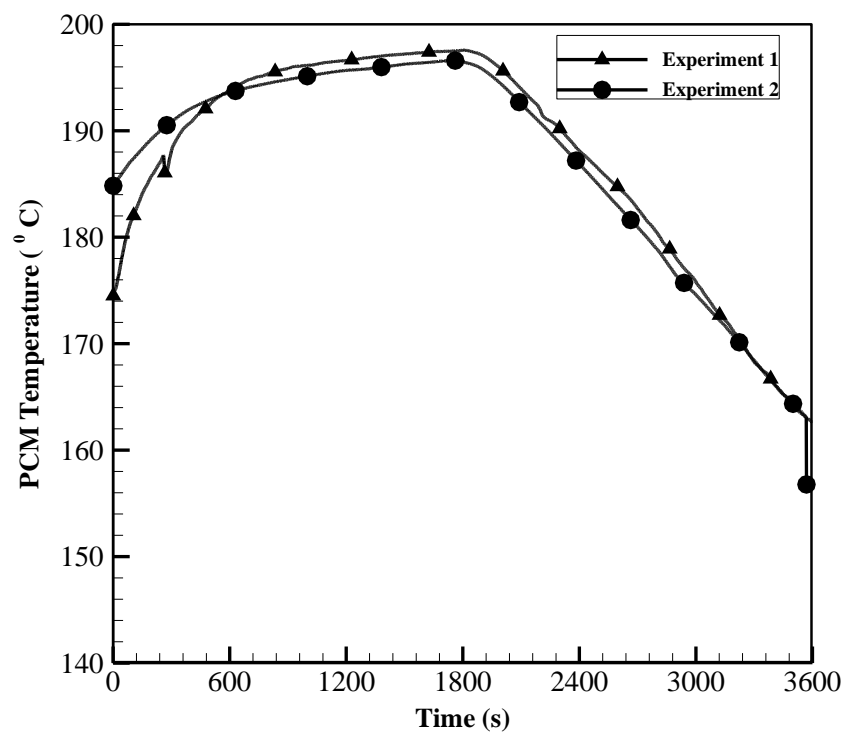

Fig. 4: Variation of PCM temperature at thermocouple 6 (TC6) with time for two experiments.

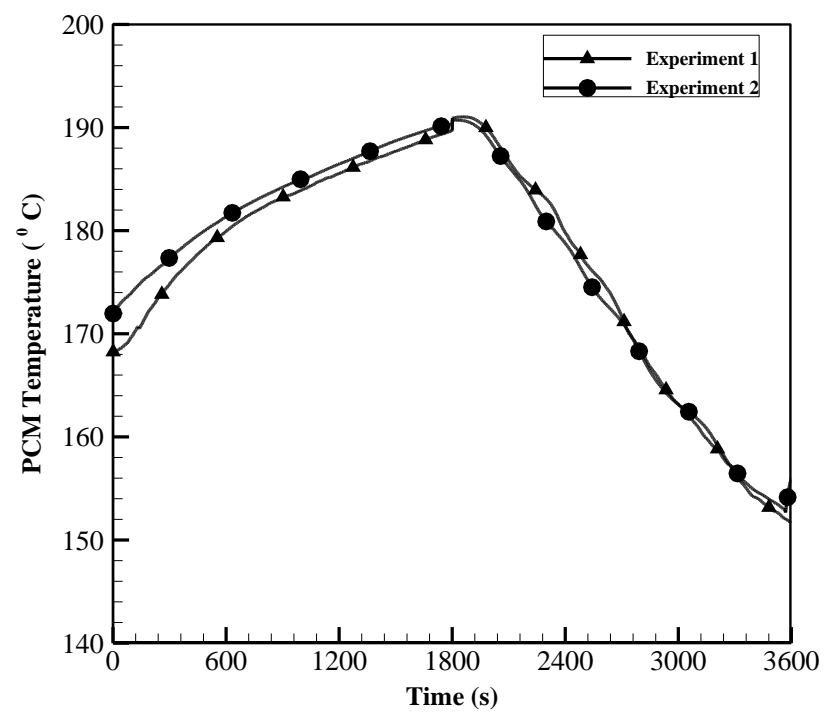

Fig. 5: Variation of PCM temperature at thermocouple 9 (TC9) with time for two experiments. 


\section{Results and Discussion}

The LHTES considered in present study is experimentally investigated. The quantity and quality of energy transfer between HTF and PCM decides the performance of storage system. As discussed above the TES experimental setup is shell and tube type with six internal tube in which HTF (Hytherm 600) is flowing and interacts with the PCM during charging and discharging. To understand the phenomenon of heat transfer the distribution of temperature in the PCM during the course of charging and discharging is studied. As mentioned in earlier, thermocouples are positioned inside the PCM to detect the temperature with time. To obtain a continuous contour of temperature at several instants, the readings of thermocouples are interpolated over a rectangular cut section of PCM from the annulus. The section is cut in such a way that left boundary represents the interface of PCM and HTF tube. The width and height are taken equal to the inner radius $(\sim 50 \mathrm{~mm})$ and height $(\sim 800 \mathrm{~mm})$ of the shell. The temperature contours thus obtained at different time during charging and discharging is shown in figures 6. During charging, it be observed that the PCM at the top left corner is heated up early as compared to other parts of the PCM. The drop in PCM temperature along the length is due to lower heat transfer between HTF and PCM. Heat transfer between HTF and PCM during discharging also starts from the top left. However, a non-uniform distribution of temperature contour during initial period of discharging is due to slow cooling of HTF from 200 to $137.4{ }^{\circ} \mathrm{C}$ and also due to the reason that temperature of PCM is already low at the bottom part after the charging period.

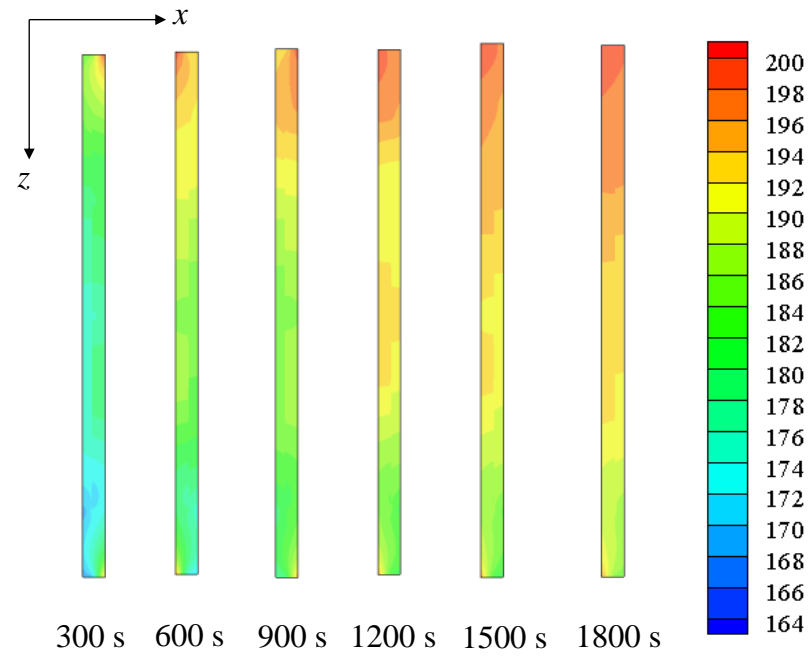

(a)

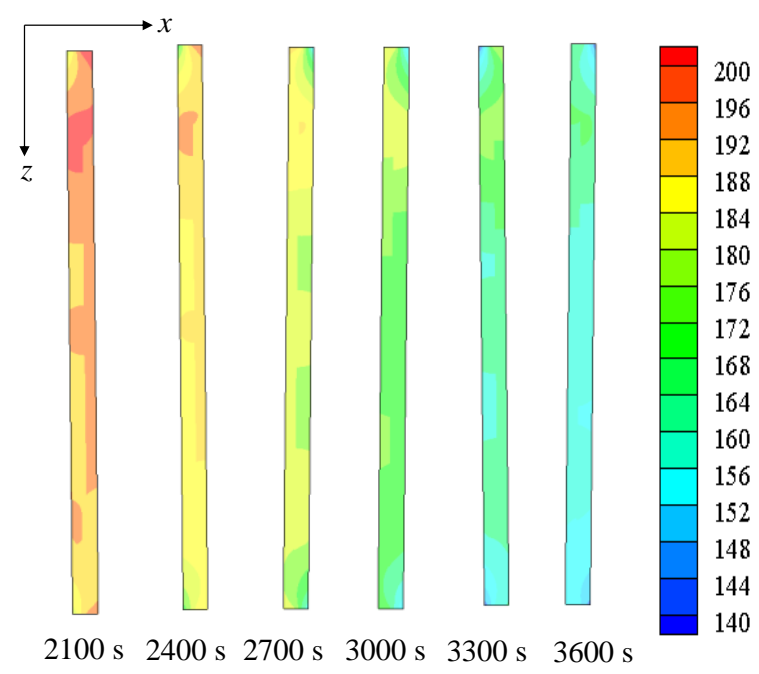

(b)

Fig. 6: Temperature contours in PCM at different time during (a) charging (b) discharging.

\subsection{Effect of HTF Inlet Temperature}

To study the effects of HTF inlet temperature on the performance of LHTES, experiments are performed with different HTF inlet temperatures. The initial temperature of PCM is kept in the range of $162 \pm 2.5^{\circ} \mathrm{C}$ below the melting temperature of PCM, i.e. $168.7^{\circ} \mathrm{C}$. The mass flow rate is set to $0.085 \mathrm{~kg} / \mathrm{s}$ for all the experiments. Three inlet temperatures of HTF 180, 190 and $200{ }^{\circ} \mathrm{C}$ is considered during charging to examine the effect on heat transfer between HTF and PCM. For the discharging period, the corresponding inlet HTF temperature is set at $157.4,147.4$ and $137.4{ }^{\circ} \mathrm{C}$. The inlet HTF temperature during and changing and discharging period is taken in such a way that the temperature difference between melting point and the inlet temperature of HTF can be kept constant. Figure7 shows the transient variation of HTF inlet and outlet temperatures during $1800 \mathrm{~s}$ of charging and discharging for different HTF inlet temperatures. It can be observed that the difference between inlet and outlet temperature of HTF for inlet HTF temperature of $200{ }^{\circ} \mathrm{C}$ is maximum as compared to the other two inlet HTF temperatures. The maximum difference in inlet and outlet temperature of HTF occurs at the start of charging due to more temperature gradient between HTF and PCM. As the charging progresses, the gradient reduces and as a result the gap between the HTF inlet and outlet temperature decreases. The average temperature difference between inlet and outlet temperatures of HTF over the course of charging for inlet HTF temperature of $200,190,180{ }^{\circ} \mathrm{C}$ is $5.07,4.95$, and $3.52{ }^{\circ} \mathrm{C}$, respectively. The maximum average difference in $\mathrm{HTF}$ inlet and outlet temperature is observed at inlet HTF temperature of $200^{\circ} \mathrm{C}$, hence it can be concluded that more heat transfer during charging takes place between PCM and HTF at higher inlet HTF temperature. Heat transfer during discharging period is calculated based on the difference of outlet HTF temperature at the end of charging and at the end of discharging. It is found that for inlet HTF temperature of $200,190,180{ }^{\circ} \mathrm{C}$, this difference is $52.2,38.3,23.7{ }^{\circ} \mathrm{C}$. Hence, during 
discharging of the storage, heat transfer between the HTF and the PCM is maximum at the highest temperature difference. To understand the performance at different inlet HTF temperatures, the efficiency is calculated which is defined as the ratio of heat released to the heat accepted by the PCM from HTF. Energy efficiency at inlet HTF temperatures of 200, $190,180^{\circ} \mathrm{C}$ is $41.3 \%, 38.53 \%$ and $31.29 \%$, respectively. Thus this can be concluded that with the increase in inlet HTF temperature, more heat transfer rate and efficiency can be achieved. This can be justified by the fact that the maximum heat transfer between the PCM and the HTF occurs when the difference between the average PCM temperature and the HTF is high. It can be observed that although the efficiency at higher inlet HTF temperature is more, the rate of increase in efficiency reduces as the inlet temperature in increased.

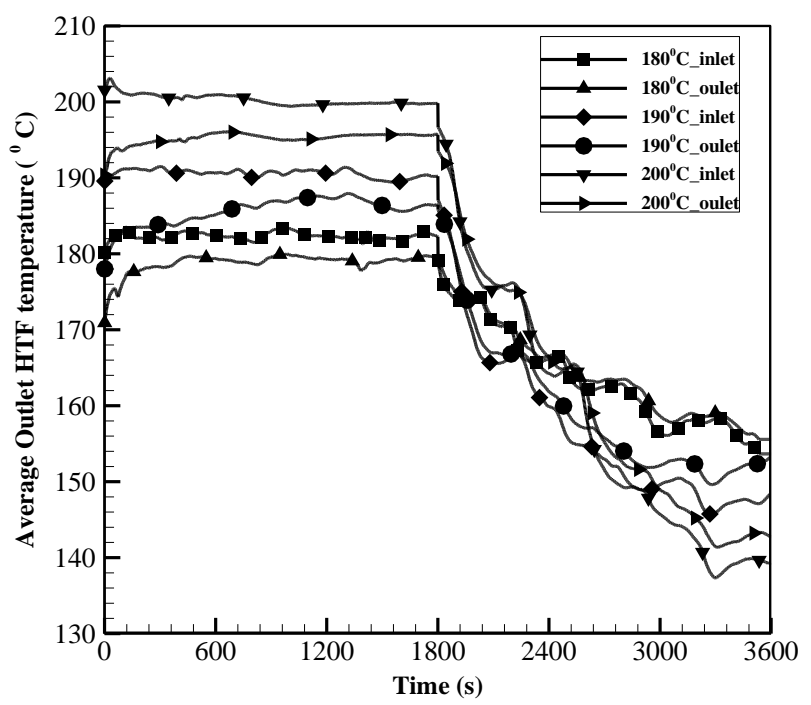

Fig. 7: Variation of HTF outlet temperature with time for different HTF inlet temperatures.

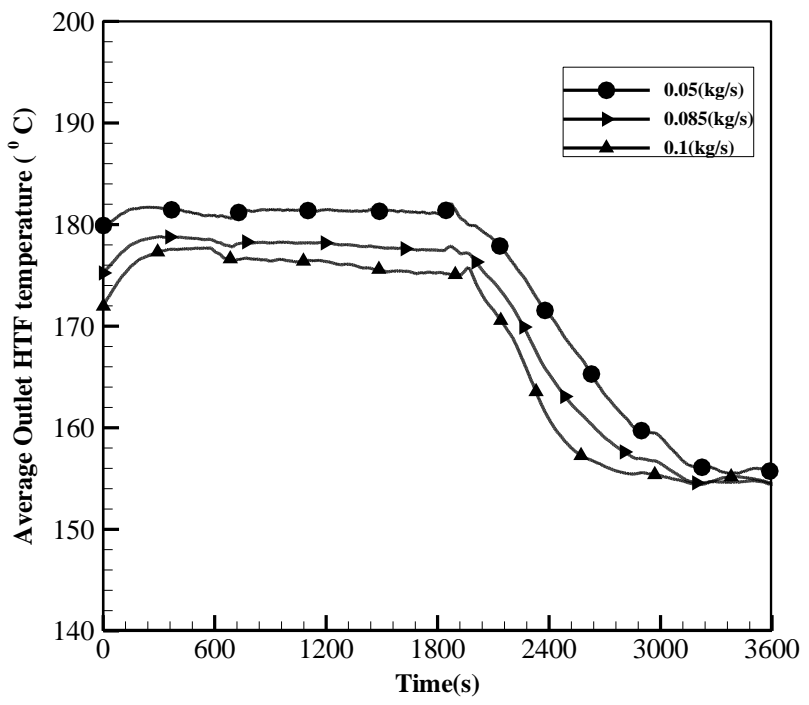

Fig. 8: Variation of HTF outlet temperature with time for different flow rates for $T_{i n}=185^{\circ} \mathrm{C}$.

\subsection{Effect of Mass Flow Rate}

A set of experiments is performed to study the effect of mass flow rate on the LHTES. The inlet temperature of HTF is kept constant at $185^{\circ} \mathrm{C}$. The initial temperature is also taken in the range of $162 \pm 2.5^{\circ} \mathrm{C}$. Three mass flow rates 0.1 , 0.085 , and $0.005 \mathrm{~kg} / \mathrm{s}$ is considered to evaluate the effect on the heat transfer and efficiency of LHTES. Figure 8 shows the variation of outlet HTF temperature with time for different mass flow rates. It can be observed that the outlet temperature of HTF at the start of charging is $180.2,174.6$ and $171.95{ }^{\circ} \mathrm{C}$ for the mass flow rate $0.005,0.085$ and 0.1 $\mathrm{kg} / \mathrm{s}$ respectively. Subsequently, a sharp rise in the temperature is observed to $181.4{ }^{\circ} \mathrm{C}$ in $78 \mathrm{~s}, 179.1{ }^{\circ} \mathrm{C}$ in $62 \mathrm{~s}$ and $176.86^{\circ} \mathrm{C}$ in $57 \mathrm{~s}$ for the flow rate of $0.005,0.085$, and $0.1 \mathrm{~kg} / \mathrm{s}$ respectively. Afterwards, the change in HTF temperature over the charging period is not significant. The average difference between the inlet HTF temperature and outlet HTF temperature during charging is maximum for the mass flow of $0.1 \mathrm{~kg} / \mathrm{s}$. Thus, heat transfer between the HTF and the 
PCM is maximum for high flow rate as higher convective heat transfer can be achieved at high flow rate. During discharging process, the inlet temperature is set at $152.4{ }^{\circ} \mathrm{C}$ and the same observation as charging process is made for the discharging period. The energy efficiency is also calculated for better understating of the performance at different mass flow rates. The efficiency is calculated as $33 \%, 31.2 \%$ and $28.06 \%$ for the flow rate of $0.1,0.085$, and $0.005 \mathrm{~kg} / \mathrm{s}$.

\section{Conclusions}

In the present work, heat transfer characteristics of multitube LHTES during charging and discharging period is studied experimentally for medium temperature solar applications. Commercial grade PCM (A164) with melting point of $168.7^{\circ} \mathrm{C}$ is used to store energy, while for HTF, Hytherm 600 is used. Temperature profile during charging and discharging is obtained to understand the heat transfer in PCM. In charging, the melting of PCM starts from the top of the LHTES and then melt front moves from top to bottom. It is found that the HTF inlet temperature and mass flow rate of HTF affect the performance of the LHTES. Maximum efficiency of $41.35 \%$ is found for the highest inlet temperature of HTF. However, the rate of improvement in the thermal efficiency reduces with the increase in HTF inlet temperature. Heat transfer between HTF and PCM during charging as well as in discharging process increases with increasing flow rate of HTF.

\section{Nomenclature}

\begin{tabular}{|c|c|c|c|}
\hline$c_{p}$ & Specific heat $(\mathrm{J} / \mathrm{kg} . \mathrm{K})$ & $E$ & Error \\
\hline$k$ & Thermal conductivity $(\mathrm{W} / \mathrm{m} \cdot \mathrm{K})$ & $L$ & Latent heat $(\mathrm{J} / \mathrm{kg})$ \\
\hline$T$ & Temperature & $Q$ & Heat transfer rate $(W)$ \\
\hline \multicolumn{4}{|c|}{ Greek Symbol } \\
\hline$\beta$ & Thermal expansion coefficient $\left(K^{-1}\right)$ & $\eta$ & Efficiency \\
\hline$\rho$ & Density $\left(k g / m^{3}\right)$ & $\mu$ & Dynamic Viscosity $(\mathrm{kg} / \mathrm{m} . \mathrm{s})$ \\
\hline \multicolumn{4}{|c|}{ Subscript } \\
\hline$a b s$ & Absolute & $\exp$ & Experimental \\
\hline avg & Average & in & Inlet \\
\hline$c$ & Charging & $m$ & Melting \\
\hline$d$ & Discharging & out & Outlet \\
\hline
\end{tabular}

\section{Acknowledgements}

This paper is based on work supported in part under the US-India Partnership to Advance Clean Energy-Research (PACE-R) for the Solar Energy Research Institute for India and the United States (SERIIUS), funded jointly by the U.S. Department of Energy under Subcontract DE-AC36-08GO28308 to the National Renewable Energy Laboratory and the Government of India, through the Department of Science and Technology under Subcontract IUSSTF/JCERDCSERIIUS/2012 dated 22nd Nov. 2012.

\section{References}

[1] N. Sharifi, S. Wang, T. L. Bergman, and A. Faghri, "Heat pipe-assisted melting of a phase change material," International Journal of Heat and Mass Transfer, vol. 55, no. 13-14, pp. 3458-69, 2012.

[2] Y. Wang, L. Wang, N. Xie , X. Lin, and H. Chen, "Experimental study on the melting and solidification behavior of erythritol in a vertical shell-and-tube latent heat thermal storage unit," International Journal of Heat and Mass Transfer, vol. 99, pp. 770-81, 2016.

[3] F. Agyenim, P. Eames, and M. Smyth, "A comparison of heat transfer enhancement in a medium temperature thermal energy storage heat exchanger using fins," Sol. Energy, vol. 83, pp. 1509-1520, 2009.

[4] Z. X. Gong and A. S. Mujumdar, "Finite-element analysis of cyclic heat transfer in a shell-and-tube latent heat energy storage exchanger," Appl. Therm. Eng., vol. 17, no. 6, pp. 583-591, 1997.

[5] T. Silva, R. Vicente, F. Rodrigues, A. Samagaio, and C. Cardoso, "Development of a window shutter with phase change materials: Full scale outdoor experimental approach," Energy and Buildings, vol. 88, pp. 110-121, 2015.

[6] A. H. Mosaffa, F. Talati, M. A. Rosen, and H. B. Tabrizi, "Approximate analytical model for PCM solidification in a rectangular finned container with convective cooling boundaries," International Communications in Heat and Mass Transfer, vol. 39, no. 2, pp. 318-324, 2012.

[7] K. Bhagat, and S. K. Saha, "Numerical analysis of latent heat thermal energy storage using encapsulated phase change material for solar thermal power plant," Renewable Energy, vol. 95, pp. 323-336, 2016. 
[8] P. Muthukumar, and H. Niyas, "Comparison of Thermal Characteristics of Sensible and Latent Heat Storage Materials Encapsulated in Different Capsule Configurations," Concentrated Solar Thermal Energy Technologies, pp. 11-20, Springer, Singapore, 2018.

[9] A. Trp, K. Lenic, and B. Frankovic, "Analysis of the influence of operating conditions and geometric parameters on heat transfer in water-paraffin shell-and-tube latent thermal energy storage unit," Appl. Therm. Eng., vol. 26, pp. 1830-1839, 2006.

[10] H. A. Adine, and H. E. Qarnia, "Numerical analysis of the thermal behaviour of a shell-and-tube heat storage unit using phase change materials," Applied mathematical modelling., vol. 33, pp. 2132-2144, 2009.

[11] E. Oroa, and A. Gila, "Thermal energy storage implementation using phase change materials for solar cooling and refrigeration applications," Energy Procedia, vol. 30, pp. 947 - 956, 2012.

[12] A. Shinde, S. Arpit, K. M. Pramod, P. V. C. Rao, and S. K. Saha, "Heat transfer characterization and optimization of latent heat thermal storage system using fins for medium temperature solar applications," Journal of Solar Energy Engineering ASME, vol. 139, pp. 031003, 2017. 